\title{
Role of the Spike Protein in Murine Coronavirus Induced Hepatitis: An in vivo Study Using Targeted RNA Recombination
}

\author{
${ }^{1}$ SONIA NAVAS , ${ }^{1}$ SU-HUN SEO, ${ }^{1}$ MING MING CHUA, ${ }^{2}$ JAYASRI DAS \\ SARMA, ${ }^{3}$ SUSAN T. HINGLEY, ${ }^{2}$ EHUD LAVI, AND ${ }^{1}$ SUSAN R. WEISS \\ ${ }^{\prime}$ Department of Microbiology, and ${ }^{2}$ Department of Pathology and Laboratory Medicine, \\ University of Pennsylvania School of Medicine, Philadelphia, Pennsylvania; ${ }^{3}$ Department of \\ Microbiology, Philadelphia College of Osteopathic Medicine, Philadelphia, Pennsylvania.
}

\section{INTRODUCTION}

Various strains of the murine coronavirus, mouse hepatitis virus (MHV), have been shown to display different organ tropism and pathogenesis, including enteritis, encephalitis, demyelination and hepatitis in C57BL/6 mice (Perlman et al., 1998). Infection of mice by MHV is an experimental model of chronic demyelinating diseases, such as multiple sclerosis (Buchmeier et al., 1999). Furthermore, some MHV strains can be considered as a model for studying acute and chronic hepatitis of viral etiology (Ding et al., 1997). It is well established that the severity of MHV-induced hepatitis is dependent on virus strain. MHV-A59 induces moderate to severe hepatitis, whereas MHV-4 (an isolate of MHV-JHM strain) produces none to minimal hepatitis. MHV-2 is a highly hepatotropic strain that causes severe hepatitis. However, the viral determinants which explain the differences in pathogenicity are poorly understood.

Until very recently, the study of viral determinants of pathogenesis was limited to the comparison of different strains and mutant viruses. This 
type of approach has demonstrated that mutations in the spike (S) gene were associated with altered pathogenicity (Fleming et al., 1989; Rowe et al., 1997; Leparc-Goffart et al., 1997). We have previously characterized fusion-defective mutants of MHV-A59, which were derived from persistently infected glial cell cultures (Gombold et al., 1993). C12, one of these fusion-defective A59 mutants, was attenuated and displayed an altered hepatotropism (Hingley et al., 1994). The spike gene of C12 contains only two mutations: i) one in the cleavage site of the $\mathrm{S}$ protein, $\mathrm{H} 716 \mathrm{D}$ was previously shown to be responsible of the fusion defect phenotype; ii) the second mutation (Q159L) was found in the receptor binding domain of the $\mathrm{S}$ protein and its presence was associated with the loss of the hepatotropic phenotype (Leparc-Goffart et al., 1997). We further derived hepatitisproducing revertants through 8 in vivo passages of $\mathrm{C} 12$ through the livers of mice (Hingley et al., 1995). Interestingly, both Q159L as well as H716D were maintained but, two additional mutations in the spike gene appeared: R654H and E1035D.

Genetic manipulation of MHV genome has been recently available with the development of targeted RNA recombination (Koetzner et al.; Masters, 1999). Using this technique, we have recently demonstrated that the spike protein is a major determinant of neuropathogenic properties of MHV (Phillips et al., 1999). In a previous study, we found that a Q159L amino acid substitution introduced by targeted RNA recombination into the spike gene of MHV-A59 alter the ability of the virus to replicate efficiently in the liver and induce hepatitis (Leparc-Goffart et al., 1998). By means of targeted RNA recombination we are currently beginning to map viral determinants of hepatotropism within the spike protein.

\section{METHODS}

\subsection{Targeted RNA recombination}

We have compared three isogenic recombinant viruses that differ only in the spike gene, expressing the spike protein of A59 $\left(\mathrm{S}_{\mathrm{A} 5 \mathrm{~g}} \mathrm{R} 13\right)$, MHV-4 ( $\left.\mathrm{S}_{4} \mathrm{R} 21\right)$ and MHV-2 (Penn98-1), all in the A59 background. The construction of this recombinant viruses has been described elsewhere (Phillips et al., 1999; Das Sarma et al., 2000).

The hepatitis revertants (HR2) recombinants (R173, R174) were constructed following a recent modification (Kuo et al., 2000). 


\subsection{Virulence assays}

Fifty-percent lethal dose $\left(\mathrm{LD}_{50}\right)$ assays were carried out as described previously (Leparc-Goffart et al., 1998). Mice were inoculated intracranially with fivefold serial dilutions of wild-type and recombinant viruses. Mice were examined for signs of disease or death on a daily basis for up to 21 days postinfection. LD50 values were calculated by the Reed-Muench method (Smith et al., 1997).

\subsection{Viral replication in infected tissue}

C57BL/6 mice were infected intrahepatically (ih) with 500 plaque forming units (PFU) of virus as described previously (Hingley et al., 1994). Virus in homogenized liver tissue was titered, in duplicate, by plaque assay on L2 cell monolayers in 6-well micotiter plates.

\subsection{Liver histology and immunohistochemistry}

Mice were sacrificed at selected times postinfection and perfused with 10 $\mathrm{ml}$ of PBS and livers were removed. Formalin-fixed tissue was embedded in paraffin, sectioned and stained with hematoxylin and eosin (H\&E) for histological diagnosis. Hepatitis was scored as mild (1), moderate (2) and severe (3). Immunohistochemical analysis was performed by the avidinbiotin-immunoperoxidase technique (Vector Laboratories, Burlingame, Calif.). As a primary antibody we used a monoclonal antibody (Mab) against the nucleocapsid protein $(\mathrm{N})$ of MHV-JHM strain (Mab clone 1-161 , kindly provided by J.L. Leibowitz). All slides were read blindly and mock-infected controls were included.

\section{RESULTS AND DISCUSSION}

Preliminary data obtained in this study are shown in Table 1. After i.h. inoculation with $500 \mathrm{PFU}$ per virus, the peak of replication was at day 5 postinfection (p.i.). The replication pattern of each recombinant was similar to the corresponding parental virus. Penn98-1 showed the higher viral titers (range $10^{7}-10^{8} \mathrm{PFU} / \mathrm{g}$ tissue) than $\mathrm{S}_{\mathrm{A} 59} \mathrm{R} 13\left(10^{6}-10^{7} \mathrm{PFU} / \mathrm{g}\right.$ tissue, whereas $\mathrm{S}_{4} \mathrm{R} 21$ presented a very low level of hepatic replication $\left(10^{3}-10^{4} \mathrm{PFU} / \mathrm{g}\right)$. Regarding the hepatic damage, Penn 98-1 produced severe hepatitis, 
whereas $\mathrm{S}_{4} \mathrm{R} 21$ induced only none to mild hepatitis. The liver damage produced by $\mathrm{S}_{\mathrm{A} 59} \mathrm{R} 13$ was moderate to severe hepatitis. Viral antigen staining colocalized with necrotic areas in the Penn 98-1 and $\mathrm{S}_{\mathrm{A} 5} \mathrm{R} 13$. In $\mathrm{S}_{4} \mathrm{R} 21$, specific viral staining was found in hepatocytes with conserved cellular morphology.

Table 1. Intrahepatic replication, hepatic injury and viral staining observed in recombinant viruses.

\begin{tabular}{ccccc}
\hline $\begin{array}{c}\text { Recombinant } \\
\text { virus }\end{array}$ & Spike gene & ih replication $^{\mathrm{a}}$ & Liver histology $^{\mathrm{b}}$ & Viral staining $^{\mathrm{c}}$ \\
\hline $\mathrm{S}_{\mathrm{A} 59} \mathrm{R} 13$ & $\mathrm{~A} 59$ & ++ & $2-3$ & ++ \\
Penn98-1 & MHV-2 & +++ & 3 & +++ \\
$\mathrm{S}_{4} \mathrm{R} 21$ & MHV-4 & $+/-$ & $0-1$ & $+/-$ \\
$\mathrm{R} 173$ & $\mathrm{~A} 59^{*}$ & +++++ & $\mathrm{ND}^{\mathbb{1}}$ & $\mathrm{ND}^{\mathbb{1}}$ \\
\hline
\end{tabular}

a viral titers in liver at day 5 p.i.: $++++++\left(\right.$ range $\left.10^{9}-10^{10}\right) ;+++\left(10^{7}-10^{8}\right) ;++\left(10^{6}-10^{7}\right)$; $+\left(10^{4}-10^{6}\right) ;+/-\left(10^{3}-10^{4}\right) ;$ ranges are expressed as PFU/g tissue.

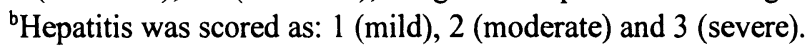

'Immunohistochemistry showed viral antigen staining in the hepatic parechyma. The extension and the intensity of the staining are scored as $+/-($ low $),+$ (medium) and high $(+++)$.

*A59 hepatitis revertant spike gene has only four mutations in comparison with A59 spike: Q159L, R654H, H716D and E1035D.

"ND, not done.

Recombinants viruses with the spike of the hepatitis revertants (HR2) were also constructed. The HR2 recombinants showed high virulence and replication ability in the liver (Table 1 and 2).

Table 2. Virulence and type of spike protein of various parental and recombinant viruses.

\begin{tabular}{ccc}
\hline Virus & Spike protein & Log (LD50) \\
\hline MHV-A59 & A59 & 3.8 \\
S $_{\text {A59 }}$ R16 & A59 & 3.8 \\
C12 & Q159L, H716D & 6 \\
R36 & Q159L, H716D & 5.1 \\
HR2 & Q159L, H716D & 1.2 \\
& R654H, E1035D & \\
R173 & Q159L, H716D & 1.0 \\
& R654H, E1035D & \\
\hline
\end{tabular}

Taking together these data, underline a direct role of the MHV spike glycoprotein in the development of hepatitis in infected mice. The role of the $\mathrm{S}$ protein in the pathogenesis is consistent with its biological function. The $\mathrm{S}$ protein, found on the virion envelope and on the plasma membrane of infected cells is responsible for the attachment to cellular receptor and viruscell fusion during viral entry and for cell-to-cell fusion later during infection. One interesting hypothesis is that mutations in the spike may 
account for an altered interaction with the cellular receptor. In particular, the Q159L mutation is in the putative receptor-binding domain of the spike. We previously demonstrated by targeted recombination that the Q159 is a determinant of hepatotropism (Leparc-Goffart et al., 1998). The hepatitis revertant virus (HR2) were originated by in vivo passages of the $\mathrm{C} 12$ through the liver of C57BL/6 mice. Sequencing of the spike of this HR2 virus showed that two new mutations (R654H, E1035D) in the spike appeared whereas those observed in the C12 (Q159L, H716D) were maintained. We have constructed a recombinant virus with the HR2 spike mutants in the A59 background. Interestingly, this HR2-spike recombinant virus replicates in the liver to 2 logs over the A59 and even 3 logs over the highly hepatotropic MHV-2 virus in the liver. As recombinants virus A59R16, R36 and HR2R173 are isogenic virus that differs only in the above mentioned mutations in the spike gene, it can be argued that the $\mathrm{R} 654 \mathrm{H}$, E1035D are playing an important role in the dramatic differences observed in liver replication. Thus, in hypothesis, one or both of the two mutations may account for the highly hepatotropic phenotype of the hepatitis revertant virus.

In summary, by means of targeted RNA recombination we found direct correlation between mutations in the murine coronavirus spike protein and hepatotropism.

\section{REFERENCES}

Buchmeier, M.J., and Lane, T.E. Viral-induced neurodegenerative disease. Curr Opinion Microbiol 1999; 2:398-402.

Das Sarma, J., Fu L., Tsai, J., Weiss, S.R., and Lavi, E. Demyelination determinants map to the spike gene of coronavirus mouse hepatitis virus. J Virol 74:9206-9213.

Ding, J.W., Ning, Q., Liu, M.F., Lai, A., Leibowitz, J., Peltekian, K.M., Cole, E.H., Fung, L.S., Holloway, C., Marsden, P.A., Yeger, H., Phillips, M.J., Levy, G.A. Fulminant hepatic failure in murine hepatitis virus strain 3 infection: tissue-specific expression of a novel $f g l 2$ prothrombinase. J Virol 1997; 71:9223-92-30.

Fleming. J.O., Trousdale, M.D., El-Zaatari, F.A.K., Stohlmam, S.A., Weiner, L.P. Pathogenicity of antigenic variants of murine coronavirus JHM selected with monoclonal antibodies. J Virol 1989; 58:869-875.

Gombold, J.L., Hingley, S.T., Weiss, S.R. Fusion-defective mutants of mouse hepatitis virus A59 contain a mutation in the spike protein cleavage signal. J Virol 1993; 67:4504-4512.

Hingley, S.T., Gombold, J.L., Lavi, E., Weiss S.R. MHV-A59 fusion mutants are attenuated and display altered hepatotropism. Virology 1994; 200:1-10.

Hingley, S.T., Gombold, J.L., Lavi, E., Weiss, S.R. Hepatitis mutants of mouse hepatitis virus strain A59. Adv Exp Med Biol 1995; 380:577-582.

Koetzner, CA., Parker, M.M., Richard, C..S., Sturman, S., Masters, P.S. Repair and mutagenesis of the genome of a deletion mutant of the murine coronavirus mouse hepatitis virus by targeted RNA recombination. J Virol 1992; 66:1841-1848. 
Kuo l., Godeke, G.J., Raamsman, J.B., Masters, P.S., Rottier, P. Retargeting of coronavirus by substitution of the spike glycoprotein ectodomain: crossing the host cell species barrier. J Virol 2000; 74:1393-1406.

Leparc-Goffart, I., Hingley, S.T., Chua, Jiang, X., Lavi, E., Weiss, S.R. Altered pathogenesis of a mutant of the murine coronavirus MHV-A59 is associatted with a Q159L amino acid substitution in the spike protein. Virology 1997; 239:1-10.

Leparc-Goffart, I., Hingley, S.T., Chua, M.M., Phillips J., Lavi, E., Weiss, S.R. Targeted recombination within the spike gene of murine coronavirus mouse hepatitis virus-A59: Q159 is a determinant of hepatotropism. J Virol 1998; 72:9628-9636.

Masters, P.S. Reverse genetics of the largest RNA viruses. Advances Virus Research 1999; 53:245-264.

Perlman, S. Pathogenesis of coronavirus-induced infections. Review of pathological and immunological aspects. In: Coronaviruses and Arteriviruses. L. Enjuanes, S.G. Sidell and W. Spaan, ed. Plenum Press, New York, 1998.

Phillips, J.J., Chua M.M., Lavi, E., Weiss, S.R. Pathogenesis of MHV4/MHV-A59 recombinant viruses: the murine coronavirus spike protein is a major determinant of neurovirulence. J Virol 1999; 73:7752-7760.

Rowe, C.L., Baker, S.C., Nathan, M.J., Fleming, J.O. Evolution of mouse hepatitis virus: detection and characterization of spike deletion variants during persistent infection. $\mathrm{J}$ Virol 1997; 71:2959-2969.

Smith, A.L., Barthold, S.W. Methods in viral pathogenesis. In: N. Nathanson (ed.), Viral pathogenesis. Lippincott-Raven, Philadelphia, 1997. 